\title{
Desvelando a concepção de saúde em um grupo de crianças inseridas em atividades de promoção da saúde
}

\author{
Unveiling the notion of health in a group of children included in health promotion \\ activities'
}

Fernanda Brenner Morés', Esalba Silveira²

\footnotetext{
' Cursando Especialização em Residência Multiprofissional em Saúde, com Ênfase em Saúde da Família e Comunidade, pela Pontifícia Universidade Católica do Rio Grande do Sul (PUCRS) - Porto Alegre (RS) Brasil.

febrmo@gmail.com.

2 Doutora em Serviço Social pela Pontifícia Universidade Católica do Rio Grande do Sul (PUCRS) - Porto Alegre (RS), Brasil.

Professora adjunta da Faculdade de Serviço Social da Pontifícia Universidade Católica do Rio Grande do Sul (PUCRS) - Porto Alegre (RS). Brasil. Assistente Social do Hospital de Clínicas de Porto Alegre - Porto Alegre (RS), Brasi

esalba@redemeta.com.br.
}

RESUMO Com o objetivo de conhecer como se expressa a concepção de saúde no cotidiano de crianças que participam de ações de educação em saúde na escola, realizouse esta pesquisa, de abordagem qualitativa, utilizando-se o Método Criativo Sensível por meio da Dinâmica do Mapa Falante. Participaram 12 crianças, com idade entre 9 e 10 anos, divididas em dois grupos, pertencentes a uma escola do município de Porto Alegre/RS. Os dados evidenciaram o entrelaçamento entre a promoção da saúde, a determinação social da saúde e o território em que se expressam na concepção ampliada de saúde. As práticas educativas contribuem para a efetivação das ações de promoção da saúde.

PALAVRAS CHAVE: Promoção da saúde; educação em saúde; crianças; condições sociais.

\begin{abstract}
With the aim of understanding how the notion of health is expressed in the everyday life of children who participate in health education activities at school, this qualitative study employed the Sensitive and Creative Method through a Speaking Map role-play exercise. Twelve children aged 9 to 10 years old from a municipal school in Porto Alegre/RS, split into two groups, participated in the study. The data revealed the intertwined relationship between health promotion, the social determination of health and the territory in which they are expressed in a broader notion of health. Educational practices contribute toward rendering health promotion actions effective.
\end{abstract}

KEYWORDS: Health promotion; health education; children; social conditions. 


\section{O Ponto de Partida: Introdução}

Os fundamentos e as práticas de promoção da saúde alicerçam-se, atualmente, em estratégias que se contrapóem aos modelos assistenciais com enfoque biologicista, individualista e reducionista.

A concepção de promoção da saúde reforça, tanto no seu conceito quanto em suas práticas, a saúde como uma produção construída socialmente, determinada por fatores biológicos, ambientais, sociais, econômicos e culturais. A partir da concepção ampla do processo saúde-doença, a promoção da saúde direciona-se para um enfoque político e técnico, e procura, por meio de suas propostas, promover açóes que sejam capazes de agir no conjunto de determinantes sociais da saúde (BYDLOWSKI; WESTPHAL; PEREIRA, 2004).

Esses preceitos inspiram-se na Carta de Ottawa (1986), onde consta que a promoção da saúde relaciona-se com fatores favoráveis ao seu pleno desenvolvimento. Nesse entendimento, destaca-se a dimensão intersetorial, pois a saúde, quando entendida de forma ampliada, transcende ao setor saúde para o âmbito do desenvolvimento social (CZERESNIA, 2003; BUSS, 2003; SÍCOLI; NASCIMENTO, 2003).

A Carta de Ottawa aponta três estratégias fundamentais da promoção da saúde: defesa da saúde, capacitação e mediação. A defesa da saúde consiste em lutar para que os fatores políticos, econômicos, comportamentais e biológicos sejam cada vez mais favoráveis à saúde. Nessa direção, a promoção da saúde pretende assegurar idênticas oportunidades e proporcionar os meios (capacitação) que permitam às pessoas atingirem seu potencial de saúde. Os indivíduos e as comunidades devem ter oportunidade de conhecer e controlar os fatores determinantes da sua saúde, elementos esses que alimentam a proposta do estudo em questão (BUSS, 2000).

Propóe, também, a utilização de campos processuais visando à promoção da saúde, cabendo destacar a criação de políticas públicas saudáveis, pois supera a ideia focada no comportamento individual. A criação de ambientes favoráveis, como escolas, locais de trabalho, entre outros, favorece e facilita as práticas de saúde, passando a formar a agenda da política de saúde.
Entende-se, ainda, como fundamental, realçar o poder técnico e político das comunidades, sobretudo através da socialização da informação e das oportunidades de aprendizagem para toda a população. Assim, contribuise para a escolha de prioridades, para a tomada de decisões e, acima de tudo, para a fundamentação das estratégias capazes de atingir uma melhoria na qualidade de saúde (BUSS, 2000).

Por isso, é necessário o desenvolvimento de habilidades e atitudes pessoais durante as etapas da vida, principalmente por meio da educação em saúde, em todos os espaços coletivos. Segundo Carvalho (2004, p. 671), a promoçáo da saúde passa a ser definida como

\section{[...] processo de capacitação de indivíduos e coletivos para que tenham controle sobre os de- terminantes de saúde, com o objetivo de terem uma melhor qualidade de vida.}

Para que esse processo se concretize, devem-se articular os campos de ação da promoção da saúde.

A melhoria na qualidade de saúde e de vida da população, a partir do exercício da cidadania, possibilita que se realizem transformaçóes nos indivíduos, tanto em caráter individual quanto coletivo, capacitando-os para atuarem no controle das situaçóes a que são submetidos. Nesse sentido, a promoção da saúde oferece a educação em saúde como uma forma de desenvolvimento para atingir esses objetivos (BYDLOWSKI; WESTPHAL; PEREIRA, 2004).

A promoção da saúde passa pela reconfiguração das práticas de educação, as quais devem se fundamentar na reflexão filosófica, não se limitando apenas à informação e à capacitação técnica. Assim, introduz-se a educação em saúde como modelo dialógico que possibilita a transformação dos saberes. Conta com o reconhecimento do usuário como sujeito portador de um saber e objetiva a emancipação e a autonomia, através do entendimento acerca do processo saúde-doença, e, ainda, a busca e a decisão por estratégias apropriadas para sua promoção. Com base no modelo dialógico, a educação em saúde torna-se uma estratégia para operacionalizar a promoção de saúde (CZERESNIA, 2003; ALVES, 2005). 
A necessidade de qualificar e ampliar as açóes de promoção nos serviços e na gestão do Sistema Único de Saúde (SUS) efetiva-se através da Política Nacional de Promoção da Saúde (PNPS), sendo que, na organização do SUS, são de competência da Atenção Básica as açôes de promoção da saúde e prevenção de agravos, destacando-se como um campo privilegiado para o desenvolvimento das ações de educação em saúde. Contribui para isso a garantia de uma maior aproximação das populaçóes pertencentes aos territórios adstritos às unidades de saúde (BRASIL, 2006).

Exige-se, então, que se atenha ao conceito de território, o qual é construído coletivamente e é compreendido como ambiente de produção da vida. Os territórios são dinâmicos e variáveis, constituindo-se em áreas de atuação, de fazer e de responsabilidade. Para atender às suas peculiaridades, as Unidades de Saúde neles se inserem. Assim, para o desenvolvimento das práticas de saúde, os territórios, sujeitos e as instituiçóes configuram-se como responsabilidade de tais serviços (BRASIL, 2009).

A ideia de território, para Santos (2009), configura-se pelas técnicas, pelos meios de produção, pelos objetos e coisas, pelo conjunto territorial e pela dialética do próprio espaço, bem como pela intencionalidade humana. Deste modo, um dos recursos que se identifica e que reconhece a sua importância para o desenvolvimento de ações de promoção da saúde é a escola. A escola considerada

\section{[...] como espaço de relaçôes e de o desenvolvimen-} to crítico e politico, contribuindo na construção de valores pessoais, crenças, conceitos de conhecer o mundo e interfere diretamente na produçâo social da saúde. (BRASIL, 2009, p.8).

A promoção da saúde na escola, de acordo com Valadão (2004, p. 4),

\section{[...] corresponde a uma visão e a um conjunto} de estratégias que têm como objetivo produzir repercussóes positivas sobre a qualidade de vida e os determinantes de saúde dos membros da comunidade escolar.
O trato dessa temática exige o entendimento do principal ator que ocupa esses espaços, que, neste caso, é a criança, a qual se inscreve num processo histórico e social que a determina e é, por ela, determinado. Àries (1981) foi um dos primeiros historiadores a entender a infância como uma construção social, enquanto Sirota (2001) considera a criança um ator em sentido pleno, configurando-se, ao mesmo tempo, produto e ator de processos sociais. Para tanto, aponta a necessidade de discutir o que a criança cria na intersecção de suas instâncias de socialização, incluindo-se a construção de crenças, valores e conceitos que referenciam as suas relaçóes, sendo que, entre eles, pode estar a concepção atinente à saúde.

Os argumentos arrolados sobre a promoção da saúde afirmam a sua relevância para as práticas de saúde. Adiciona-se a isso o reconhecimento da criança como um ator social capaz de criar e modificar culturas, e a Unidade Básica de Saúde (UBS) como lócus do trabalho. Assim, esses elementos contribuíram para a fundamentação e o desenvolvimento de um projeto de intervenção interdisciplinar de educação em saúde na escola.

O desenvolvimento do trabalho de educação em saúde numa escola, ao mesmo tempo em que reiterou a ideia de que a criança tem possibilidade de recriar seu processo de socialização e interferir na realidade social, suscitou a realização deste estudo, a fim de responder à questão: como se expressa a concepção de saúde no cotidiano de crianças que participam de ações de educação em saúde na escola? Sob tal perspectiva, o objeto de pesquisa surgiu do contexto da práxis, o que também determinou o tipo de abordagem. A promoção da saúde e a problemática em foco, bem como o seu correlato objeto de estudo, conservam, internamente, algumas particularidades que são mais bem investigadas no plano coletivo do processo grupal.

\section{O Mapa Metodológico}

Este estudo caracteriza-se pela abordagem qualitativa de tipo exploratório descritivo e abalizado no método do materialismo histórico. Dessa maneira, considerando os 
sujeitos, o tema e o problema de pesquisa, optou-se pelo Método Criativo e Sensível (MCS), que, segundo Cabral (1998), integra os instrumentos de coleta de dados utilizados nas abordagens qualitativas com as Dinâmicas de Criatividade e Sensibilidade (DCS), acrescentando os seus dispositivos próprios, como as produçóes artísticas. Ainda para fundamentar a escolha, recorre-se a Ferreira ${ }^{1}$ (2001 apud NATIVIDADE; COUTINHO; ZANELLA, 2008, p.11) para afirmar que:

\section{[...] os significados das figuraçôes do desenho da criança são culturais e produto das suas experi- ências com os objetos reais mediadas pela pala- vra e pela interação com o outro.}

Também foi possível desenvolver a dialógico-dialética, através da pedagogia crítico-reflexiva, quando os participantes constroem o significado que foi produzido por meio da coletivização das suas produçóes artísticas, assim, gerando temas a serem debatidos no processo coletivo. A produção possibilita, também, ao participante falar de si, provocando seus valores e suas crenças. Segundo Cabral (1998, p. 180), “[...] as dinâmicas de criatividade e sensibilidade favorecem a libertação parcial dos sentidos reprimidos, das palavras que se calam".

Por meio da linguagem lúdica artística e da discussão grupal, o grupo torna-se sujeito do conhecimento produzido, superando a condiçáo de objeto, e, com isso, passa a valorizar a dimensão social e coletiva do conhecimento. Concomitantemente, permite a validaçáo da pesquisa, pois o grupo vai confirmando e particularizando o comum e o incomum. Assim, este estudo fundamentou-se na discussão de grupo, na dinâmica de criatividade e de sensibilidade e na observaçáo participante (CABRAL, 1998).

O cenário da pesquisa foi uma escola de ensino fundamental, situada no município de Porto Alegre, localizada em bairro inserido num dos maiores complexos de pobreza, pertencente à área adscrita à UBS. Para a delimitação dos sujeitos, utilizou-se a amostragem não probabilística, através da modalidade intencional, sendo esta utilizada no MCS. Os sujeitos da pesquisa foram doze alunos, de 9 a 10 anos, de ambos os gêneros, com mais frequência e assiduidade. As crianças que participaram do projeto de intervenção encontravam-se em situação de vulnerabilidade social. Conjuntamente com os profissionais da escola, procuraram-se outras crianças na mesma condição. Os participantes foram divididos em dois grupos de seis, sendo que um grupo foi formado por aqueles que participaram do projeto de intervenção de educação em saúde e o outro por alunos que não o vivenciaram.

A pesquisa respeitou os aspectos éticos, conforme Resolução n. 196/96, do Conselho Nacional de Saúde (BRASIL, 1996), que dispóe a respeito das Normas de Pesquisa com Seres Humanos, sendo, portanto, aprovada pelo Comitê de Ética em Pesquisa (CEP) da Pontifícia Universidade Católica do Rio Grande do Sul, Protocolo n. 11/05403, e pelo CEP da Secretaria Municipal de Saúde, da Prefeitura Municipal de Porto Alegre/RS, Processo n. 001.011027.11.8. Além de ter sido autorizada pela Secretaria Estadual de Educação, responsável pela escola onde se efetivou a pesquisa.

Após aprovação pelos CEPs das instituições envolvidas, foi apresentado o projeto de pesquisa para a direção e para os professores da escola. Isso possibilitou envolvê-los na seleção dos sujeitos para participar do estudo, a qual foi seguida por uma reuniáo com os pais e responsáveis das crianças para apresentação do projeto e do termo de consentimento livre e esclarecido. Assegurou-se, dessa forma, o direito à privacidade, à confidencialidade das informações e à preservação da identidade dos envolvidos.

Entre as dinâmicas da criatividade e sensibilidade, escolheu-se a do Mapa Falante, que, referendado na concepção de território, é utilizado como instrumento para a leitura da realidade e para promover a discussão sobre a saúde a partir de seus determinantes. Tal instrumento é sugerido pelo Ministério da Saúde pela sua propriedade de construir, coletivamente, processos educativos em saúde na escola (BRASIL, 2005).

FERREIRA, S. apud NATIVIDADE, M. R.; COUTINHO, M. C.; ZANELLA, A. V. Desenho na pesquisa com crianças: análise na perspectiva histórico-cultural. Contextos Clínicos, São Leopoldo, v. 1, n. 1, p.9-18, jan.-jun. 2008. Disponível em: < http://www.contextosclinicos.unisinos.br/pdf/41.pdf>. Acesso em: 20 jun. 2011. 
Para a execução do encontro, além do pesquisador, foi convidado um auxiliar de pesquisa, que registrou os acontecimentos, observou a linguagem não verbal e as atividades práticas.

A coleta dos dados ocorreu em dois grupos distintos, de seis alunos cada, com apenas uma abordagem em cada grupo, seguindo a sequência de momentos sugerida pelo MCS. O espaço para realização da pesquisa foi previamente organizado com os materiais para o desenvolvimento da atividade (folhas A4 coloridas, lápis, lápis de cor, giz de cera, massa de modelar, revistas, objetos lúdicos, materiais recicláveis, revistas, gravuras, entre outros).

No primeiro momento, a pesquisadora e os participantes apresentaram-se, e foi concedido o termo de assentimento, o qual foi lido utilizando-se de termos compatíveis com o entendimento da criança. Através do termo, foi explicado o objetivo da dinâmica. A discussão grupal e a produção artística foram desenvolvidas por meio das questões geradoras: 1) O que é saúde? 2) O que se precisa para ter saúde? 3) O que tem no bairro onde você mora que se relaciona com a saúde? 4) $\mathrm{O}$ que saúde tem a ver com escola? 5) O que tem na cidade onde você mora que se relaciona com saúde?

Após a discussão grupal, iniciou-se a composição das produçóes, quando os participantes foram construindo, em uma grande folha de EVA, o conceito de saúde, seguindo a lógica de território. Por fim, fez-se a coletivização das experiências individuais. Através da análise coletiva dos dados e da validação, quando as produçôes são discutidas, as informaçóes foram sistematizadas, dessa forma, verificando a aproximação e o distanciamento dos conteúdos construídos coletivamente.

Os dados da pesquisa foram submetidos à análise de conteúdo e, pela proposta, à técnica de análise temática. As expressóes verbais do grupo foram registradas por meio de gravadores, transcritas e agrupadas junto com as observações. As produções construídas através do mapa falante reiteram e validam as categorias presentes. Para apresentação dos resultados, optou-se pela promoção da saúde como categoria analítica; como categorias empíricas, a concepção de saúde, território e determinantes sociais do processo de saúde doença. As principais subcategorias da concepção de saúde foram: moradia, alimentação, trabalho, saneamento básico; na categoria território, destacaram-se delegacia, hospitais, escola, transporte e praças; nos determinantes de saúde, selecionaram-se violência, dependência química e ausência de saneamento básico. As subcategorias foram divididas respeitando a frequência das unidades de significação e o significado, conforme assinala Minayo (1994), pois os seus significantes estavam presentes em mais de uma categoria.

\section{O Mapa da Chegada: Resultados e Discussões}

O desenvolvimento do presente estudo possibilitou identificar que a promoção da saúde encontra, na escola, um espaço privilegiado para o desenvolvimento de práticas realizadas com sujeitos sociais críticos e criativos, capazes de construir conhecimentos, relaçôes e ações que fortaleçam a participação das pessoas na busca de vidas mais saudáveis, sendo que, para isso, passa, em alguma medida, pela concepção de saúde que vai sendo construída.

As crianças manifestavam-se ativamente diante das questôes geradoras. Naquela que perguntava "o que é saúde?", os participantes foram porta-vozes de diferentes entendimentos sobre o tema, tal como ainda está posto na realidade social, como: "É estar bem, só isso!"; "Ir ao médico quando tiver uma doença, para se tratar [...]"; "Tomar injeção, ir ao médico". A saúde também é referida através de bons hábitos de higiene: "Lavar as mâos antes de comer", "Escovar os dentes"; "Ter boa higiene"; "Passar fio dental"; "Escovar os dentes três vezes ao dia"; "Tomar banho". Identificouse que, num primeiro momento, elas revelaram com maior facilidade a hegemonia do modelo biomédico, a partir da influência que exerce sobre a população, que acaba compreendendo saúde como ausência de doença, tratamento médico ou práticas individuais e higienistas. Tal evidência vai ao encontro de Batistella (2007, p. 25), quando afirma que, "[...] cotidianamente, expressamos compreensóes sobre saúde e doença”, o que enseja, dialeticamente, inferir que as práticas realizadas nos serviços de saúde, da vida cotidiana dessas 
crianças, também se relacionam a uma visão restritiva da questão saúde.

Reconhecendo que os meios materiais e as teias de relaçóes para o desenvolvimento e a realização das capacidades, aos quais os indivíduos têm acesso em suas vidas, definem possibilidades e formam características das existências individuais, as crianças foram provocadas a pensar e a adicionar outros elementos à saúde, e, então, relataram: "Saúde é comer"; "É comer alimentos saudáveis"; "É comer frutas e verduras, banana, alface, feijão e arroz". Assim, surge o acesso à alimentação, e, pelo compartilhamento de ideias, as crianças identificam que precisam de alimentos saudáveis.

$\mathrm{O}$ processo de reflexão em torno de saúde e alimentação as leva a identificar um novo componente, que é o trabalho, como integrante desse processo: "E para ter saúde tem que trabalhar, para pagar as contas, as comidas"; "Para ter casa tem que trabalhar, colocar serviço no corpo. A base de tudo é o trabalho".

A discussão possibilita a manifestação sobre as condiçôes de trabalho como formas alternativas para sobrevivência: "Se estiver com dor, mesmo assim, tem que trabalhar para poder comer"; "Para quem não consegue serviço, que não tem toda hora, para eles completarem, eles vendem latinhas, trabalham no lixo orgânico". Essas revelaçóes corroboram o que refere Teixeira (2009, p. 384): "[...] as condiçôes sociais são efetivamente base para o padrão sanitário de um povo, assim como a posição de cada indivíduo na sociedade é uma base da própria saúde”. Deste modo, as crianças, paulatinamente, trouxeram para o cenário o conceito ampliado como saldo de um processo condicionado por diversos fatores, como alimentação e nutrição, habitação e saneamento, educação, trabalho, justiça social, ecossistema, entre outros. Com isso, o processo de saúde-doença nas coletividades ocorre a partir das dimensōes econômicas, sociais e políticas, assim como o resultado das formas de organização social pode gerar desigualdades nos diferentes níveis de vida (BRASIL, 1988).

Recorre-se, nesse particular, a Mario Quintana, quando enuncia: "Olho o mapa da cidade/Como quem examinasse /A anatomia de um corpo [...]". E a Santos (2009), quando define que o território é a plataforma na qual os homens exercem a sua história. Este reitera que os territórios são espaços construídos socialmente, e, para isso, remete à necessidade de conhecê-los, tal como afirmou Quintana. A promoção da saúde ratifica a relevância e entende o território como espaço da organização das suas práticas. E a proposta do mapa falante, associado às questóes geradoras, convidou as crianças a prospectar sobre o território no qual se inserem, na sua relação com o processo saúde-doença.

Assim como Quintana pronuncia que "Há tanta esquina esquisita /Tanta nuança de paredes [...]", um dos participantes apresenta o bairro como "uma rua e um monte de casas". A dinâmica possibilitou, em seu espaço dialógico, reconstruir opinióes e transformá-las em conhecimento mais crítico, então, aparece a coleta de lixo, o saneamento: "Eu tiro lixo e levo lá para os lixeiros levarem. Tem um lugar perto da minha casa que é uma casa cheia de garrafas pet e lixo que eles juntam. É reciclagem"; "Quando usar o vaso, dar a descarga”. $\mathrm{Na}$ construção do mapa, reproduzem as moradias e as suas condiçóes. E, assim, paulatinamente, amplia-se o espaço do território do âmbito das casas para a comunidade, e produzem:

Uma delegacia, uma casa, árvore e a casa de
frutas. Delegacia para prender os ladróes, o
hospital para atender os que estäo doentes, a
casa de frutas para vender frutas e a casa para
morar. Se não tivesse os policiais, podiam ter
matado muitas pessoas, assaltado o mercado e a
banca de frutas.

Como Monken e Barcellos (2007) afirmam, os recursos sustentam a reproduçáo da vida social, estabelecendo, entre as pessoas, fluxo de materialidade e equipamentos sociais. Por isso, a sua significação real para a vida social sucede das açóes realizadas sobre eles, as quais podem promover ou limitar as açóes humanas. Assim, as crianças, ao identificarem os espaços e recursos existentes, como o transporte, praças e comércio, expressam as suas relaçóes e conexóes. "Tem o supermercado que vende os alimentos saudáveis e não vende drogas"; "Se não tivesse ônibus perto das coisas para ir ao colégio, nós não íamos poder estudar. Se não tivesse padaria nas ruas, não íamos comprar pão"; "Jogar 
futebol, andar de bicicleta, fazer um churrasco, brincar”. Portanto, é fundamental a articulação e a interação entre todas as coisas que farão daquele lugar um lugar saudável para viver.

Ainda dentro dessa compreensão de território, os serviços de saúde, como hospitais, unidades de saúde, incluindo também as farmácias, são relacionados como espaços produtores de saúde. Destaca-se, aqui, que ambos os grupos produziram, graficamente, esses espaços na construção do mapa falante, aparecendo mais hospitais do que unidades de saúde.

\section{O lugar que tem mais saúde no mundo éo hos-} pital, porque arruma as pessoas, dá saúde para as pessoas, faz as pessoas sentirem mais saúde. A todo momento, tem gente lá.

A presença no mapa falante de muitos hospitais foi justificada: "Se tiver um todo ocupado, tem o outro".

Segundo Campos (2003), as desigualdades, tanto no uso dos serviços quanto no acesso aos mesmos, referem-se às diferenças no comportamento do indivíduo perante o processo saúde-doença, considerando, também, as características das ofertas de serviços disponibilizadas pela sociedade aos seus membros. Com isso, reforça a aproximação dos serviços de saúde com os indivíduos e a comunidade, que concretiza o vínculo entre população e profissionais e, assim, reforça as açōes da promoção da saúde. A discussão grupal possibilitou um novo olhar diante do significado do hospital com relação à saúde: "Para ter saúde, tem que procurar mais alimentos saudáveis, coisas saudáveis. O hospital é só para melhorar saúde, não para ter saúde”.

As açóes de promoção da saúde concretizam-se em espaços sociais e tratam de situaçóes de existência que expressam determinadas condiçôes de saúde. Consideram-se, portanto, em geral, os espaços das cidades e das comunidades campos de atuação da promoção da saúde, dentre os quais, destaca-se a escola (MONKEN; BARCELLOS, 2007).

A questão geradora - "O que saúde tem a ver com a escola?" - pretendia identificar se ela seria reconhecida como produtora de saúde, e, primeiramente, as crianças associaram o acesso à alimentação: lanche.
Seguindo-se de manifestaçóes que reconhecem o uso coletivo dos equipamentos como geradores ou não de práticas que promovem a saúde, como "Limpar os banheiros"; "Não riscar nas paredes"; "Limpar o colégio"; "Varrer a sala depois da aula". E identificaram, também, as atividades desenvolvidas, como: "Educação Física"; "Tem Professor"; "Estudar"; "Escrever"; "Tu vai aprender". A partir daí, os alunos começam a dar um novo significado à escola, como um espaço de produção de saúde, ao relacioná-la como possibilidade de melhores condiçóes de vida: "Para ser alguém na vida"; "[...] nunca vai ter uma profissáo boa". Os alunos passam a relacionar a escola como um meio de alcançar os determinantes de saúde: "Ter um trabalho bom"; "Comprar casa, comida".

Conforme Monken e Barcellos (2007, p.184), "[...] para compreender as açóes das pessoas e suas práticas no dia a dia, deve-se identificar como a vida acontece a partir do nível mais local". As práticas sociais cotidianas materializam-se a partir das condiçóes necessárias à subsistência humana, e poderão condicionar comportamentos e práticas.

$\mathrm{Na}$ categoria dos determinantes sociais da saúde e dos seus enfrentamentos, buscou-se identificar as características sociais dentro das quais a vida transcorre, bem como questóes específicas do contexto social que afetam a saúde e a maneira como as condições sociais foram traduzidas pelas crianças, no que se referia ao impacto sobre a saúde. Compreender saúde, diante das especificidades dos contextos de territórios, aproxima-se da produção social dos problemas de saúde nos diversos lugares onde a vida acontece.

Os determinantes arrolados pelos alunos não tiveram relação direta com a doença ou agravos, típicos do setor saúde, mas relacionavam-se à ausência do saneamento básico: "Nada no meu bairro tem saúde"; "Só tem cachorro com sarna, pulga, carrapato e lixo";

Lá na minha rua, colocam o lixo em cima, para quando o lixeiro chegar e pegar, mas os cachorros pegam o saco, rasgam, e, quando vem a chuva, leva tudo, entope os bueiros";

"Entope os bueiros e daí alaga tudo". 
Teixeira (2009) destaca que há campos de determinantes sociais que vão além da exposição de risco de danos fisiológicos, que são característicos da pobreza, mas são igualmente intensos e, comumente, denominados psicossociais, como a violência e as drogas: "Não faz bem para a saúde"; "Tem que parar um pouco com os bandidos, de assaltar, de matar"; "Eu vi uma reportagem que um pai pegou um pedaço de madeira e bateu nos filhos, e um guri maior gravou tudo e levou na delegacia para explicar tudo que aconteceu"; "No meu bairro, tem pessoas que usam drogas".

A análise dos dados aponta para o entrelaçamento entre a promoção da saúde, a determinação social da saúde e o território em que se expressam na concepção ampliada de saúde.

\section{O Mapa do Tesouro: Considerações Finais}

A dinâmica do mapa falante foi referida pelas crianças como o "Mapa do Tesouro", o que se considerou como uma apropriada analogia ao que se pretende no trabalho de promoção da saúde. $\mathrm{O}$ mapa do tesouro oferece aos seus participantes a rota a ser seguida até atingirem o tesouro, ainda que, para isso, tenham de superar muitos desafios, avanços e retrocessos, até chegarem ao tesouro: produção de saúde.

A operacionalidade da dinâmica motivou a participação ativa dos sujeitos, sobretudo por se tratar de crianças, e a diversidade de materiais disponibilizados estimulou a criatividade e a sensibilidade para a construção do produto final: o mapa. Entende-se, também, que a atividade se reveste do conceito de promoção da saúde, e que a linguagem artística e a discussão grupal, por sua vez, tornam-se uma ação educativa. A dinâmica propicia a validação do conhecimento produzido e, a partir da sistematização dos dados, o próprio grupo identifica a aproximação e o distanciamento dos conteúdos construídos coletivamente.

Destaca-se, diante dos elementos construídos no mapa falante, a presença de delegacia e de polícia. Os significantes desses temas relacionam-se ao setor de segurança pública, no entanto, o significado atribuído pelas crianças é o de que delegacia e polícia produzem saúde. A análise desses conteúdos, expressos na produção e nas falas dos sujeitos, ratifica os princípios da promoção da saúde e o conceito ampliado de saúde, que se refere à intersetorialidade como estratégia de enfrentamento dos determinantes de saúde. Conforme apontam Campos, Barros e Castros (2004), a intersetorialidade não deve ser vista como única estratégia a ser utilizada nos diferentes territórios e populaçôes, ela deve mobilizar os setores necessários para responder às necessidades de saúde de uma coletividade, desse modo, entrelaçando todos os atores envolvidos, principalmente a população, devendo sua participação ocorrer desde o diagnóstico da situação até a avaliação das ações implantadas.

Outro dado a ser destacado neste estudo é a ausência da palavra doença, já que as crianças substituíam-na por "não é saúde", e, assim, traziam para discussão os determinantes do processo saúde-doença apresentados neste trabalho.

A promoção da saúde propóe a mudança do modelo de atenção e de orientação das práticas de saúde, possuindo, como estratégia central, a constituição das políticas públicas saudáveis e o desenvolvimento de habilidades pessoais. Assim, por meio da concepçáo ampliada de saúde, esses campos devem ser desenvolvidos de forma articulada, favorecendo a estruturação de políticas públicas voltadas para a qualidade de vida e de saúde, e o fortalecimento da população para o controle dos determinantes sociais em saúde. Com isso, potencializa-se o modelo assistencial de saúde pautado na promoção da saúde.

Por fim, recorre-se, novamente, a Quintana, ao encontrar nas ações de promoção da saúde, a partir do conceito ampliado de saúde, a possibilidade de mudança na vida e nas condiçôes de saúde da população: "Há tanta moça bonita/Nas ruas que não andei/ (E há uma rua encantada/Que nem em sonhos sonhei $[\ldots])$ ". 


\section{Referências}

ALVES, V. S. Um modelo de educação em saúde para o Programa Saúde da Família: pela integralidade da atenção e reorientação do modelo assistencial. Interface - Comunicação, Saúde e Educação, Botucatu, v. 9, n. 16, p. 39-52, fev. 2005. Disponível em: < http:// www.scielo.br/pdf/icse/v9n16/v9n16a04.pdf >. Acesso em: 24 out. 2010.

ÀRIES, P. História Social da Criança e da Família. 2. ed. Rio de Janeiro: LTC, 1981.

BATISTELLA, C. Saúde, Doença e Cuidado: complexidade teórica e necessidade histórica. In: FONSECA, A. F; CORBO, A. M. D'A. (orgs.). O território e o processo saúde-doença. Rio de Janeiro: EPSJV/FIOCRUZ, 2007. p. 25-50.

BRASIL. Constituição da República Federativa do Brasil. Brasília, DF: Senado Federal, 1988.

Ministério da Saúde. Secretária de Atenção à Saúde. Departamento da Atenção Básica. Saúde na Escola. Brasília: Ministério da Saúde, 2009. (Caderno de Atenção Básica, n. 24. Série B. Textos básicos de Saúde).

Ministério da Saúde. Secretaria de Gestão do Trabalho e da Educação na Saúde. Departamento de Gestão da Educação na Saúde. A educação que produz saúde. Brasília: Ministério da Saúde, 2005. (Série F. Comunicação e Educação em Saúde) Disponível em: <http://bvsms.saude.gov.br/bvs/publicacoes/educacao_que_ produz_saude.pdf>. Acesso em: 20 out. 2010.

Resolução no 196, de 10 de outubro de 1996. Aprova as diretrizes e normas regulamentadoras de pesquisas envolvendo seres humanos. Disponível em: <http://conselho. saude.gov.br/ resolucoes/1996/Reso196.doc >. Acesso em: 4 out. 2010.

Secretaria de Atenção à Saúde. Departamento de Atenção Básica. Política Nacional de Atenção Básica. Brasília: Ministério da Saúde, 2006. (Série Pactos pela Saúde, v. 4. Série A. Normas e Manuais Técnicos). Disponível em: <http://bvsms.saude.gov.br/ bvs/ publicacoes/politica_nacional_atencao_basica_2006.pdf>. Acesso em: 20 out. 2010.

BUSS, P. M. Uma Introdução ao Conceito de Promoção da Saúde. In: CZERESNIA, D.; FREITAS, C. M. (orgs.). Promoção da Saúde: conceitos, reflexões, tendências. Rio de Janeiro: FIOCRUZ, 2003. p. 15- 39.

. Promoção da Saúde e Qualidade de Vida. Ciência e Saúde Coletiva, Rio de Janeiro, v. 5, n. 1, p.163-177, 2000. Disponível em: < http://www.scielosp.org/pdf/csc/v5n1/7087.pdf >. Acesso em: 21 out. 2010.

BYDLOWSKI, C. R.; WESTPHAL, M. F.; PEREIRA, I. M. T. B. Promoção da Saúde. Porque sim e porque ainda não! Saúde e Sociedade, São
Paulo, v. 13, n. 1, p.14-24, jan./abr.2004. Disponível em: <http:// www.scielo.br/pdf/sausoc/v13n1/03.pdf>. Acesso em: 25 nov. 2010.

CABRAL, I. E. O método criativo e sensível: alternativa de pesquisa na enfermagem. In: GAUTHIER, J. H. M. et al. Pesquisa em enfermagem: novas metodologias aplicadas. Rio de Janeiro: Guanabara Koogan, 1998. p. 177-203.

CAMPOS, C. E. A. O desafio da integralidade segundo as perspectivas da vigilância da saúde e da saúde da família. Ciência e Saúde Coletiva, Rio de Janeiro, v. 8, n. 2, p. 569-584, 2003. Disponível em: < http://www.scielosp.org/pdf/csc/v8n2/ a18v08n2.pdf>. Acesso em: 20 jun. 2011

CAMPOS, G. W.; BARROS, R. B.; CASTRO, A. M. Avaliação da política nacional de promoção da saúde. Ciência e Saúde Coletiva, Rio de Janeiro, v. 9, n. 3, p.745 - 749, 2004. Disponível em: < http://www. scielo.br/pdf/csc/v9n3/a20v09n3.pdf >. Acesso em: 22 nov. 2010.

CARVALHO, S. R. As contradições da promoção à saúde em relação à produção de sujeitos e a mudança social. Ciência e Saúde Coletiva, Rio de Janeiro, v. 9, n. 3, p.669-678, 2004. Disponível em: <http://www.scielo.br/pdf/csc/v9n3/a13v09n3.pdf>. Acesso em: 25 nov. 2010.

CZERESNIA, D. O Conceito de Saúde e a Diferença entre Prevenção e Promoção. In: CZERESNIA, D.; FREITAS, C. M. (orgs.). Promoção da Saúde: conceitos, reflexões, tendências. Rio de Janeiro: FIOCRUZ, 2003. p. 39- 53.

MINAYO, M. C. O desafio do conhecimento. São Paulo: HucitecAbrasco, 1994.

MONKEN, M.; BARCELLOS, C. O território na promoção e vigilância em saúde. In: FONSECA, A. F.; CORBO, A. M. D'A. (orgs.). O território e o processo saúde-doença. Rio de Janeiro: EPSJV, FIOCRUZ, 2007. p.51-86.

NATIVIDADE, M. R.; COUTINHO, M. C.; ZANELLA, A. V. Desenho na pesquisa com crianças: análise na perspectiva histórico-cultural. Contextos Clínicos, São Leopoldo, RS, v. 1, n. 1, p.9-18, jan.-jun. 2008. Disponível em: < http://www.contextosclinicos.unisinos. br/pdf/41.pdf>. Acesso em: 20 jun. 2011.

QUINTANA, M. Quintana de bolso. Porto Alegre: L\&PM, 1997.

SANTOS, M. A natureza do espaço: técnica e tempo - razão e emoção. 4. ed. São Paulo: EDUSP, 2009.

SíCOLI, J. L.; NASCIMENTO, P. R. Promoção da Saúde: concepção, princípios e operacionalização. Interface - Comunicação, Saúde e Educação, Botucatu, v. 7, n. 12, p. 91-112, 2003. Disponível em: < 
http://www.interface.org.br/revista12/artigo3.pdf >. Acesso em: 21 out. 2010.

SIROTA, R. Emergência de uma Sociologia da Infância: evolução do objeto e do olhar. Cadernos de Pesquisa, São Paulo, n. 112, 2001. Disponível em: <http://www.scielo.br/pdf/cp/n112/16099.pdf>. Acesso em: 30 out. 2010.
TEIXEIRA, P. F. Uma introdução conceitual à determinação social da saúde. Saúde em debate, Rio de Janeiro, v. 33, n. 83, p. 380-387, set./dez. 2009.

VALADÃO, M. M. Saúde na Escola: um campo em busca de espaço na agenda intersetorial. 2004. 154f. Tese (Doutorado em Serviços de Saúde) - Faculdade de Saúde Pública, Universidade de São Paulo, São Paulo, 2004.

Recebido para publicação em Fevereiro/2012

Versão final em Abril/2013

Conflito de interesse: não houve

Suporte financeiro: inexistente 